\title{
A Quantitative Study on Stigma and Statistically Correlated Factors Among Women Living with Genital Fistula in Oromia Region, Ethiopia. Identification of Urgent Corrective Strategies
}

\author{
Bekana Fekecha (D)', Samuel Abdu $\mathbb{D}^{2}$, Ayanos Taye $\mathbb{D}^{2}$, Biru Abdissa $\mathbb{D}^{\prime}$, Fantaye Chemir $\mathbb{D}^{3}$, \\ Gemechu Terefe (D)', Fedhesa Mamo', Kebenesa Angasu (D)', Eneyew Melkamu (D), Tariku Bekela (D) \\ 'Department of Midwifery, Jimma University, Jimma, Ethiopia; ${ }^{2}$ Department of Nursing, Jimma University, Jimma, Ethiopia; ${ }^{3}$ Department of Midwifery, \\ Wolkite University, Wolkite, Ethiopia \\ Correspondence: Kebenesa Angasu, Department of Midwifery, 378 at Jimma University Main Campus, Jimma Town, Oromia, Jimma, Ethiopia, \\ Tel +25191984I766, Email kebenesa2019@gmail.com
}

\begin{abstract}
Background: Two-to-three million women worldwide live with a genital fistula, with Asian and sub-Saharan African countries including Ethiopia accounting for the greatest percentage. Genital fistula is a devastating health problem due to the stigma associated with constant incontinence and bad-odor. Thus, this study aimed to determine the magnitude of the stigma towards women living with genital fistula in Oromia region, Ethiopia, and to highlight the factors associated with it, identifying potential strategies for corrective interventions.
\end{abstract}

Methods: This quantitative study was conducted among 422 women living with genital fistula in five fistula treatment centers of Oromia region using a cross-sectional study design from August 30, 2019 to February 28, 2020. Data were collected by face-to-face interview using a structured questionnaire, entered into Epi-data version 4.2, and analyzed by SPSS version 23 . Bivariate and multivariable logistic regression analysis was done. $P$-value $<0.05$ was used to ascertain statistical significance with an adjusted odds ratio at $95 \%$ confidence interval (CI). The results were presented by text and tables.

Results: The response rate for this study was $100 \%$. The magnitude of perceived high stigma related to genital fistula was 178 $(42.2 \%)$. The factors associated with it were the respondents' father's educational level of being able to write and read compared to unknown fathers' educational level ( $\mathrm{AOR}=0.09 ; 95 \% \mathrm{CI}=0.03-0.34$ ), and duration of living with a genital fistula of less than 2 years compared to living with a genital fistula for 5 years or more (AOR $=0.52 ; 95 \% \mathrm{CI}=0.31-0.86$ ).

Conclusion: The perceived level of stigma among women living with a genital fistula in Oromia region was significantly high. To reduce the perceived level of stigma and therefore to prevent the severe negative consequences of it, fathers, but also mothers, husbands, family members, and all the persons close to women living with genital fistulas should provide care and psychological support and all the necessary means to strongly encourage them to seek health care quickly, and to make them feel that they are beloved, and that there is hope for a healthy life in their near future.

Keywords: stigma, genital fistula, devastating health problem, Oromia region, Ethiopia

\section{Introduction}

Globally greater than 2 million women, mostly in Asia and sub-Saharan Africa, live with an obstetric fistula, while annually 50,000 to 100,000 new cases are added to this number. ${ }^{1}$ Also, in Ethiopia, an obstetric fistula is common. ${ }^{2}$ An obstetric fistula is a devastating health problem where an abnormal opening forms between a woman's genital and urinary tract and/or rectum resulting mostly from untreated prolonged obstructed labor. ${ }^{1-3}$ Thus, obstetric fistula patients suffer constant urinary and/or fecal incontinence that leads to social isolation, perianal skin infection, vast kidney problems, depression, suicide, extreme poverty, chronic health problems, and even death in untreated cases. ${ }^{1,3}$ 
Even though prevention and control of obstetric fistula results in reduced maternal morbidity and mortality, thereby contributing to an achievement of Sustainable Development Goal 3 of maternal health improvement; ${ }^{1,3}$ it is continuously prevalent in low- and middle-income countries due to harmful traditional practices such as early marriage, female genital mutilation, and lack of access to quality emergency obstetric care. ${ }^{3-5}$ Also, the continued existence of an obstetric fistula in developing countries is a clear indicator that social and health systems are failing to meet human right and reproductive health needs for the poorest and most vulnerable women. ${ }^{3,6,7}$

What makes obstetric fistula a severe and debilitating problem is the stigmatization associated with unremitting wetness and bad odor that results from it. ${ }^{8}$ Stigmatization among the fistula patients comes in different forms including explicit verbal abuse and devaluing them to be with others; women's own anticipated stigma fearing that people may talk about her; and woman's internalized stigma revealed as being shameful, loss of self-worth, and self-importance. ${ }^{9}$ Hence, significant women affected by obstetric fistula isolate themselves from social interaction, leave their usual household roles, refrain from disclosing their situation (even not seeking healthcare), and suffer different mental problems, all of which leadthem to be unable to contribute positively to their society's social, economic, and political development. ${ }^{8,9}$

Obviously, stigmatization causes the majority of women living with obstetric fistula to experience severe psychological traumas including humiliation, being marginalized, abandonment, loneliness, divorce, and despair, which are most difficult situations to bear. ${ }^{10}$ Also, they experience angriness, sadness, and shame associated with their inability to undertake their role in a decent manner, and being frightened of their future life in relation to having partners, marriage, sex, becoming pregnant, giving birth, and reintegrating back in their local communities. ${ }^{11}$

Overall, stigmatization related to genital fistula has devastating health, social, economic, and psychological consequences on the health and well-being of the affected women, which in turn affects their rehabilitation and reintegration to their families and communities even after successful fistula repair. A number of strategies should be put in place to enable the affected women to be free from stigmatization, and also to encourage them to seek healthcare quickly and live freely a productive life after fistula treatment. Unfortunately, there is a lack of relevant published studies and evidence to direct appropriate intervention in Ethiopia, especially regarding the Oromia region. In order to fill this literature gap, our study aimed to quantify the magnitude of stigma among women living with genital fistulas, and to identify its statistically associated factors. As a consequence, it will provide evidence that could have immediate practical implications for all concerned political and health bodies in establishing strategies to prevent stigmatization towards women living with genital fistulas, enabling them to seek prompt healthcare, to maximize their hope for future life, and to contribute to their families and country's overall development.

\section{Methods}

\section{Study Area, Design, and Period}

This study was conducted in five fistula treatment centers in Oromia region, namely Jimma University Medical Center, Metu Hamlin Fistula Center, Asella Hamlin Fistula Center, Harar Hamlin Fistula Center, and Hamlin Fistula Hospital in Addis Ababa. Of the five fistula treatment centers in the region, Hamlin Fistula Hospital in Addis Ababa provides comprehensive care for women living with a genital fistula. It was built in 1974, and has a large operating theater accommodating four surgical units, speciality clinics including a physiotherapy department, urodynamic and stoma clinic, pharmacy, and pathology services. It has an 120-bed capacity but sometimes the number of beds might increase to accommodate needs.

Jimma University medical center was founded in 1937, and is located in Jimma town at a distance of $352 \mathrm{~km}$ from Addis Ababa. It serves more than 15 million people, with a very wide catchment area that covers $17,500 \mathrm{~km}^{2}$. It provides fistula care in its gynecology/obstetrics unit. Metu Hamlin Fistula Center is located in Metu town, the capital of the Illubabora Zone. Metu town is $600 \mathrm{~km}$ from Addis Ababa. It serves a total of 2.1 million people with a total of 199 beds. Harar Hamlin Fistula Center was officially opened by Dr Catherine Hamlin by 2008 in the East part the country at a distance of $526 \mathrm{~km}$ from Addis Ababa. Asella Hamlin Fistula Center is located in Asella town at a distance of 175 $\mathrm{km}$ from Addis Ababa . It has 15 beds in its fistula unit. The study was conducted from August 30, 2019 to February 28, 2020 using an institution-based quantitative cross-sectional study design. 


\section{Source Population}

The source population was all mothers with genital fistula admitted to the five fistula treatment centers in Oromia region.

\section{Study Population}

The study population was all mothers with a genital fistula admitted to the five fistula treatment centers in Oromia region and were available in the hospitals during the data collection period.

\section{Inclusion Criteria}

All mothers with a genital fistula in the five fistula centers in Oromia region during the data collection period and who had the ability to communicate verbally were included.

\section{Exclusion Criteria}

Mothers with a genital fistula who were severely ill and unable to respond were excluded

\section{Sample Size Determination and Sampling Technique}

The sample size was determined by using the single population proportion formula $\left(n=(Z \alpha / 2)^{2} * P(1-P) / d^{2}\right)$, where " $n$ " is the minimum required sample size; " $\mathrm{Z} \alpha / 2$ " is the critical value on normal distribution curve at $95 \% \mathrm{CI}$, thus, it is 1.96; "P" is the proportion of women living with an obstetric fistula who experienced stigma due to their genital fistula,

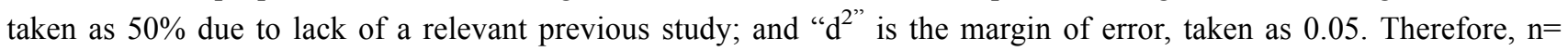
$(1.96)^{2} * 0.5(1-0.5) / 0.05^{2}$, resulting in 384 . By considering a $10 \%$ none response rate; the final sample became $384+38.4$ $\sim 422$. Thus, our final sample size was 422 . Then the sample size was proportionally allocated for the five fistula treatment centers in Oromia region depending on the trend of patient flow they had. To gain our sample size we used a consecutive sampling technique (also known as total enumerative sampling) at each facility until the calculated sample size was reached. Practically, we enrolled all women who experienced genital fistula and fulfilled the inclusion criteria from the five fistula centers in Oromia region in the order of their admission to the hospitals until the sample size was reached.

\section{Data Collection Instrument and Procedure}

A structured questionnaire, developed after reviewing relevant literature, was used for data collection. ${ }^{8-15}$ The questionnaire had three parts: Socio-demographic factors (nine items), reproductive factors (ten items), and genital fistula related stigma (14 items). The questionnaire was developed in English and translated into local languages (Afan Oromo and Amharic) and back translated into English by language experts to ensure its consistence. Before actual data collection, the questionnaire was pre-tested among 5\% of the sample size, meaning among 21 participants, in Yirgalem Hamlin fistula center, which is found in South Nation, Nationality and peoples region at around 400 $\mathrm{km}$ from Addis Ababa. Depending on the finding of the pre-test, the questionnaire was amended regarding the order of questions and selecting appropriate words and other syntax. Data collection was done by ten trained Bachelor of Science degree holder midwifery professionals through face-to-face interviews using the pre-tested questionnaire. Five Masters of Science degree holder midwives supervised the data collection procedures.

\section{Operational Definitions}

\section{Stigma}

Was considered as a state of being disgraced, ashamed, and devalued by others and/or self.

\section{Stigma Measurement Scale}

The level of perceived stigma among women living with genital fistula in Oromia region was measured by using 14 items using a 5-point Likert scale responded to as "strongly disagree" coded " 1 " to "strongly agree" coded " 5 ". The scoring was reversed for negative items. The total scores were summed up for each respondent andthe maximum possible score was " 70 " and the minimum " 14 ". Thus, the respondents who scored greater than or equal to the mean ( $\geq 35$ points) were 
considered as "perceived high stigma" related to their genital fistula and the rest considered as "perceived low stigma" related to their genital fistula.

\section{Data Analysis and Presentations}

The collected data were entered into Epi-data version 4.2 and exported to SPSS version 23 for analysis. The data were analyzed in frequency distribution, percentages, means, and cross-tabulations between the dependent and independent variables. To test the association between dependent and independent variables, binary logistic regression analysis was employed. The variables with a $p$-value $<0.25$ in bivariate analysis were identified as candidates for multivariable logistic regression analysis. Finally, variables with a $p$-value less than 0.05 in multivariable logistic regression analysis were declared as statistically significantly associated with the outcome variables. Adjusted odds ratio at a $95 \%$ confidence interval was used to express the degree to which independent variables explained the outcome variable. The results were presented by text and tables.

\section{Data Quality Control}

To ensure the quality of data, the data collectors and supervisors were trained on the objectives of the study, the contents of the questionnaires, and the way how they should politely approach the study participants to gain the necessary data. Also, before commencing the actual study the questionnaire was pre-tested and amended as needed. The completeness of the filled questionnaire was checked by the supervisors on a daily basis. Moreover, we used Epi-data version 4.2 software for data entry to minimize encountering error.

\section{Ethical Consideration}

This study was undertaken as per the declaration of Helsinki. The ethical approval was obtained from the institutional review board (IRB) of Jimma University. A letter requesting the cooperation of the five fistula treatment centers' administration was submitted to the respective fistula treatment centers. After getting permission from the respective administrators of each center, written informed consent was obtained from the study participants. For study participants whose age was below 18 years we have taken informed consent from their companion aged greater than 18 years. The anonymity and confidentiality of the study participants' information was ensured throughout by using the collected data for research purpose only.

\section{Results}

\section{Socio-Demographic Characteristics of the Respondents}

The response rate for this study was $100 \%$. Three-quarters $(314,74.4 \%)$ of the respondents were rural residents. A higher proportion $(205,48.6 \%)$ of the respondents were in the age category of $25-34$ years, with a mean and standard deviation

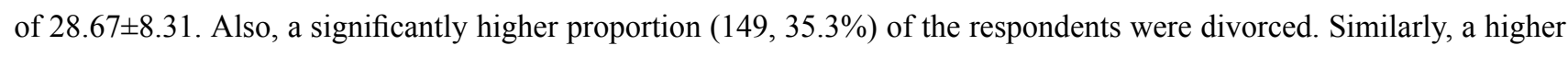
proportion $(279,66.1 \%)$ of the respondents and a higher proportion $(340,80.6 \%)$ of their father's educational status were in the category of cannot read and write (Table 1).

\section{Reproductive Health Characteristics of Respondents}

Nearly three-fifths $(246,58.3 \%)$ of the respondents age at first marriage ranged between 15-19 years. Around seven-tenth $\mathrm{s}(301,71.3 \%)$ of the respondents gave birth in governmental health facilities during which they developed their genital fistula. But three-quarters $(316,(74.9 \%)$ of the respondents gave birth after being in labor for greater than 24 hours. Just less than three-fifths $(240,56.9 \%)$ of the respondents had lived with their genital fistula for 6 weeks to 2 years. A higher proportion $(182,43.1 \%)$ of the respondents developed their fistula when they were between 15-19 years old (Table 2). 
Table I Socio-Demographic Characteristics of Women Living with Genital Fistula in Oromia Region, Ethiopia, 2019 (n=422)

\begin{tabular}{|c|c|c|c|}
\hline Variables & Category & Frequency & Percent (\%) \\
\hline \multirow[t]{5}{*}{ Age category } & $5-14$ & 2 & 0.5 \\
\hline & $15-24$ & 119 & 28.2 \\
\hline & $25-34$ & 205 & 48.6 \\
\hline & $35-44$ & 74 & 17.5 \\
\hline & $\geq 45$ & 22 & 5.2 \\
\hline \multirow[t]{4}{*}{ Marital status } & Never married & 14 & 3.3 \\
\hline & Married & 251 & 59.5 \\
\hline & Divorced/Separated & 149 & 35.3 \\
\hline & Widowed & 8 & 1.9 \\
\hline \multirow[t]{5}{*}{ Obstetric fistula case's educational status } & Cannot read and write & 279 & 66.1 \\
\hline & Read and write & 32 & 7.6 \\
\hline & Primary schools & 79 & 18.7 \\
\hline & Secondary school & 24 & 5.7 \\
\hline & College/university & 8 & 1.9 \\
\hline \multirow{6}{*}{$\begin{array}{l}\text { Obstetric fistula case's husband educational } \\
\text { status }\end{array}$} & Cannot read and write & 198 & 46.9 \\
\hline & Read and write & 46 & 10.9 \\
\hline & Primary schools & 60 & 14.2 \\
\hline & Secondary school & 49 & 11.6 \\
\hline & College/university & 15 & 3.6 \\
\hline & Do not know & 42 & 10 \\
\hline \multirow{5}{*}{$\begin{array}{l}\text { Obstetric fistula case's father educational } \\
\text { status }\end{array}$} & Cannot read and write & 340 & 80.6 \\
\hline & Read and write & 31 & 7.3 \\
\hline & Primary schools & 9 & 2.1 \\
\hline & Secondary school & 8 & 1.9 \\
\hline & Do not know & 34 & 8.1 \\
\hline \multirow{5}{*}{$\begin{array}{l}\text { Obstetric fistula case's mother educational } \\
\text { status }\end{array}$} & Cannot read and write & 376 & 89.1 \\
\hline & Read and write & II & 2.6 \\
\hline & Primary schools & 7 & 1.7 \\
\hline & Secondary school & I & 0.2 \\
\hline & Do not know & 27 & 6.4 \\
\hline
\end{tabular}

\section{Perceived Level of Stigma and Associated Factors Among Women Living with Genital} Fistula in Oromia Region

Almost half of the women living with genital fistulas (178, 42.2\%) perceived high stigma related to their condition. Even though different socio-demographic and reproductive variables were associated with the level of perceived stigma at the 
Table 2 Reproductive Related Characteristics of Women Living with Genital Fistula in Oromia Region, Ethiopia, 2019 ( $\mathrm{n}=422$ )

\begin{tabular}{|c|c|c|c|}
\hline Variables & Category & Frequency & Percent (\%) \\
\hline \multirow[t]{5}{*}{ Age at first marriage } & $5-9$ & 10 & 2.4 \\
\hline & $10-14$ & 111 & 26.3 \\
\hline & $15-19$ & 246 & 58.3 \\
\hline & $20-24$ & 43 & 10.2 \\
\hline & $\geq 25$ & 12 & 2.8 \\
\hline \multirow[t]{5}{*}{ Age of husband at first marriage } & $5-14$ & 6 & 1.5 \\
\hline & $15-24$ & 178 & 43.4 \\
\hline & $25-34$ & 192 & 46.8 \\
\hline & $35-44$ & 30 & 7.3 \\
\hline & $\geq 45$ & 4 & 1 \\
\hline \multirow[t]{4}{*}{ Age at occurrence of genital fistula } & $10-14$ & 29 & 6.9 \\
\hline & $15-19$ & 182 & 43.1 \\
\hline & $20-24$ & 88 & 20.9 \\
\hline & $\geq 25$ & 123 & 29.1 \\
\hline \multirow[t]{4}{*}{ Place of delivery during occurrence of the fistula } & Government health facility & 301 & 71.3 \\
\hline & Private health facility & 6 & 1.4 \\
\hline & At home & 111 & 26.3 \\
\hline & $\begin{array}{l}\text { On the way to health } \\
\text { facility }\end{array}$ & 4 & 1 \\
\hline \multirow[t]{4}{*}{ Duration of labor during occurrence of the fistula } & $\leq 24$ & 106 & 25.1 \\
\hline & $25-48$ & 113 & 26.8 \\
\hline & $49-72$ & 98 & 23.2 \\
\hline & $\geq 73$ & 105 & 24.9 \\
\hline \multirow{3}{*}{$\begin{array}{l}\text { Traveling time on foot from respondents' home to the } \\
\text { nearest health facility (in hours) }\end{array}$} & $\leq 12$ & 387 & 91.7 \\
\hline & $12-24$ & 26 & 6.2 \\
\hline & $>24$ & 9 & 2.1 \\
\hline \multirow[t]{3}{*}{ How long lived with genital fistula } & $0.13-2$ years & 240 & 56.9 \\
\hline & $2.25-4$ years & 55 & 13 \\
\hline & $\geq 5$ years & 127 & 30.1 \\
\hline
\end{tabular}

bivariate analysis, only two variables were statistically significantly associated with the outcome variable at the multivariable logistic regression analysis: the fathers' educational status, and length of time the respondents had lived with the genital fistula.

The odds of perceived high level of stigma were $83 \%$ less frequent among women whose father's educational status was in the category "can't read and write", and $91 \%$ less in the category "read and write", respectively, as compared to those of women who did not know their father's educational status (AOR $=0.17 ; 95 \% \mathrm{CI}=0.07-0.45$; and $\mathrm{AOR}=0.09$; 
Table 3 Bivariate and Multivariable Analysis of Factors Associated with Perceived Level of Stigma Among Women Living with Genital Fistula in Oromia Region, Ethiopia, $2019(n=422)$

\begin{tabular}{|c|c|c|c|c|c|}
\hline \multirow[t]{2}{*}{ Variables } & \multirow[t]{2}{*}{ Category } & \multicolumn{2}{|c|}{$\begin{array}{l}\text { Perceived Level of } \\
\text { Stigma }\end{array}$} & \multirow[t]{2}{*}{ COR } & \multirow[t]{2}{*}{ AOR } \\
\hline & & High & Low & & \\
\hline \multirow[t]{5}{*}{$\begin{array}{l}\text { Obstetric fistula case's father's educational } \\
\text { status }\end{array}$} & $\begin{array}{l}\text { Cannot read and } \\
\text { write }\end{array}$ & $\begin{array}{l}135 \\
(39.7 \%)\end{array}$ & $\begin{array}{l}205 \\
(60.3 \%)\end{array}$ & $0.27(0.06-1.2)$ & $0.17(0.07-0.45) * *$ \\
\hline & Read and write & $9(29 \%)$ & $22(71 \%)$ & $0.13(0.02-0.76)$ & $0.09(0.03-0.34) * *$ \\
\hline & Primary schools & $5(55.6 \%)$ & $4(44.4 \%)$ & $0.96(0.09-9.38)$ & $0.47(0.08-2.75)$ \\
\hline & Secondary school & $5(62.5 \%)$ & $3(37.5 \%)$ & $0.44(0.04-4.66)$ & $0.34(0.05-2.29)$ \\
\hline & Do not know & $24(70.6 \%)$ & $10(29.4 \%)$ & I & 1 \\
\hline \multirow[t]{3}{*}{ Length of time lived with genital fistula } & $0.13-2$ years & $84(35 \%)$ & $156(65 \%)$ & $0.47(0.26-0.86)$ & $0.52(0.3 \mathrm{I}-0.86) *$ \\
\hline & $2.25-4$ years & 25 (45.5\%) & $30(54.5 \%)$ & $0.69(0.3|3-| .5 \mid)$ & $0.74(0.37-1.49)$ \\
\hline & $\geq 5$ years & 69 (54.3\%) & $58(45.7 \%)$ & I & I \\
\hline
\end{tabular}

Notes: “*”, Indicates statistical significance at $p<0.05$; “**” Indicates statistical significance at $p<0.01$.

Abbreviations: AOR, adjusted odds ratio; COR, crude odds ratio.

$95 \% \mathrm{CI}=0.03-0.34)$. Also, the odds of perceived high level of stigma were $48 \%$ lower among women who had been living with genital fistulas for less than 2 years, as compared to those who had been living with it for 5 or more years $(\mathrm{AOR}=0.52 ; 95 \% \mathrm{CI}=0.31-0.86)$ (Table 3$)$.

\section{Discussion}

This study revealed that more than four-tenths $(178,42.2 \%)$ of women living with genital fistula in the Oromia region perceived a high stigma due to the genital fistula. The factors statistically significantly associated with the perceived high stigma among the study participants were their father's educational status and the duration of time the respondents lived with their genital fistula.

The level of perceived stigma among the study participants of the current study was a novel finding as there was no study which had quantified it previously. Although there was no published study quantifying the level of stigma among genital fistula patients, a study conducted in Ghana stated that women who experienced genital fistula from obstetric cause were often highly stigmatized. ${ }^{15}$ The possible reason behind the magnitude of the perceived high level of stigma can be the traditional belief that genital fistula is not a medical condition, but it is a curse from the creator. Also, the women suffering from the genital fistula themselves may not have a better understanding on the fistula and may consider it as disgracefulness. Considering the educational status of the women living with genital fistula in Oromia region, threequarters $(279,66.1 \%)$ of them cannot read and write, indicating that the awareness they may had on genital fistula may be low. Thus, all these factors may contribute to the high level of perceived stigma related to genital fistula among the current study participants.

In the current study, the higher educational status of the fathers of women living with genital fistulas (stated as "can read and write") was associated with the lowest odds for women of experiencing perceived high level of stigma, as compared to women who did not know the educational status of their fathers. There is a lack of previously published studies that present this finding and with which we can compare our data. The impact of fathers' educational level can be due to the fact that educated fathers may better provide the psychological and economical support for their daughters affected by genital fistulas. This is particularly significant since women affected by the genital fistula are often divorced (about one third of respondents in our study) and therefore go back to their father's and mother's house, where fathers may spend time with their affected daughters, creating the caring and loving atmosphere these women highly need. 
Finally, life with genital fistulas for a shorter period of time (between 6 weeks and 2 years) was associated with less odds of perceived high level of stigma, as compared to the group of women who lived with a fistula for 5 or more years. Again, there is no published study to compare this data with, at present. From our data, it could be extrapolated that women who have to endure life with a genital fistula for longer periods of time may become hopeless of being cured and expose themself to anticipated and internalized high levels of stigma. ${ }^{9}$ On the other hand, women who lived with the fistula for less than 2 years may show a better understanding of their health status and get better healthcare, as the information regarding fistula care is being disseminated through different media.

\section{Strength and Limitations of the Study}

The findings of this study are novel since we could not find previous studies on this subject. Thus, the findings of our study could represent a novel contribution and a potential source for implementation of strategies to positively address the issue of stigmatization of women affected by genital fistulas. At different stages of this study, we have undertaken data quality control measures; including training the data collectors and supervisors, pre-testing the questionnaire, checking for completeness of filled questionnaires, and using appropriate software for data entry and analysis. The shortage of previous studies for further comparison could be a limitation.

\section{Conclusions}

The perceived level of stigma among women living with genital fistula in Oromia region, Ethiopia, is significantly high. Factors associated with it are the fathers' educational level and the longer duration of time the woman had been living with the fistula. To reduce the perceived level of stigma and to avoid the severe negative consequences associated with it, it is crucial that fathers (and also mothers, husbands, and all peoples close to women living with genital fistulas) provide psychological and all necessary support to enable them to seek prompt healthcare, to feel that they are beloved and cared for, and to trust that there is hope for a healthy life in the future. Also, government and non-government institutions along with volunteers should work to increase awareness in the patients and in their communities that a fistula is not a curse from God, but is a preventable and curable medical condition.

\section{Abbreviation}

AOR, adjusted odds ratio; $\mathrm{CI}$, confidence interval; COR, crude odds ratio.

\section{Acknowledgments}

We are very thankful to Center for International Reproductive Health Training for funding this study during the data collection. Also, we acknowledge all administrative staff of the five fistula centers in Oromia region for their genuine support and facilitation all the time we requested them. Moreover, we would acknowledge our data collectors, supervisors, and our study participants for their contribution in realizing this study.

\section{Author Contributions}

All authors made a significant contribution to the work reported, whether that is in the conception, study design, execution, acquisition of data, analysis and interpretation, or in all these areas; took part in drafting, revising, or critically reviewing the article; gave final approval of the version to be published; have agreed on the journal to which the article has been submitted; and agree to be accountable for all aspects of the work.

\section{Disclosure}

All authors report no conflicts of interest in this work.

\section{References}

1. World Health Organization. Obstetric fistula on 19 February 2018. Geneva Switzerland. Available from: https://www.who.int/news-room/facts-inpictures/detail/10-facts-on-obstetric-fistula?_cf_chl_captcha_tk_=mzbTG_mL3sApif96UszwOZfizKnFdFUY6Ebc50t4glA-16394032060 -gaNycGzNB6U. Accessed December 11, $202 \overline{1}$. 
2. Getnet G, Adam W, Addisu G, Melaku B, Asmamaw D. Estimating the Prevalence and Risk Factors of Obstetric Fistula in Ethiopia: results from Demographic and Health Survey. Int J Women's Health. 2021;13:683-690.

3. United Nations Population Fund. Ending Obstetric Fistula Updated 23 May 2020. Available from: https://www.unfpa.org/obstetric-fistula. Accessed December 11, 2021.

4. Arrowsmith S, Hamlin EC, Wall LL. Obstructed labor injury complex: obstetric fistula formation and the multifaceted morbidity of maternal birth trauma in the developing world. Obstet Gynecol Surv. 1996;51(9):568-574.

5. Wall LL, Arrowsmith SD, Briggs ND, Browning A, Lassey A. The obstetric vesicovaginal fistula in the developing world. Obstet Gynecol Surv. 2005;60(7 S1):S3-S51.

6. World Health Organization Geneva Switzerland. End fistula. Restore Women's Dignity. Available from: https://www.who.int/reproductivehealth/ topics/maternal_perinatal/fistula/en/. Accessed February 1, 2022.

7. Bangser M, Mehta M, Singer J, Daly C, Kamugumya C, Mwangomale A. Childbirth experiences of women with obstetric fistula in Tanzania and Uganda and their implications for fistula program development. Int Urogynecol J. 2011;22(1):91-98. doi:10.1007/s00192-010-1236-8.

8. Andargie AA, Debu A. Determinants of obstetric fistula in Ethiopia. Afr Health Sci. 2017;17(3):671-680. doi:10.4314/ahs.v17i3.9

9. Bixby Center for Global Reproductive Health. Understanding fistula-related stigma to improve women's lives. Available from: https://bixbycenter. ucsf.edu/news/understanding-fistula-related-stigma-improve-women\%E2\%80\%99s-lives. Accessed December 11, 2021.

10. Kimani ZM, Ogutu O, Anthony K. The Prevalence and Impact of Obstetric Fistula on Women of Kaptembwa - nakuru, Kenya. Int J Appl Sci Technol. 2014;4(3):273-287.

11. Tadesse GY. a qualitative study of the experience of obstetric fistula survivors in Addis Ababa, Ethiopia. Int J Women's Health. $2014 ; 6: 1033-1043$.

12. Zemichael W. motivation of health workers and asssociated factors in public hospitals of west Amhara, North west Ethiopia. 2016:10, Available from: http://www.researchgate.net/publication/294724696. Accessed December 11, 2021.

13. Jain A, Carr D, Nyblade L. Measuring HIV Stigma and Discrimination Among Health Facility Staff: Standardized Brief Questionnaire User Guide. Washington, DC: Futures Group, Health Policy Project; 2015.

14. User guide Unpublished Work. An Index to Measure Stigma and Discrimination Exprerienced by People Living with HIV. South Africa; 2014. 43-47

15. Jarvis K, Richter S, Vallianatos H, Thornton L. Reintegration of Women Post Obstetric Fistula Repair: experience of Family Caregivers. Global Qualitative Nursing Res. 2017;4:2333393617714927.

International Journal of Women's Health

The International Journal of Women's Health is an international, peer-reviewed open-access journal publishing original research, reports, editorials, reviews and commentaries on all aspects of women's healthcare including gynecology, obstetrics, and breast cancer. The manuscript management system is completely online and includes a very quick and fair peer-review system, which is all easy to use. Visit http://www. dovepress.com/testimonials.php to read real quotes from published authors.

Submit your manuscript here: https://www.dovepress.com/international-journal-of-womens-health-journal 